\title{
(2) OPEN ACCESS \\ Paravertebral block for the prevention of chronic postsurgical pain after breast cancer surgery
}

\author{
Hakim Harkouk (1) ${ }^{1,2}$ Dominique Fletcher, ${ }^{1}$ Valeria Martinez ${ }^{3}$
}

${ }^{1}$ Anesthesia department, Hopital Ambroise-Paré, BoulogneBillancourt, France ${ }^{2}$ INSERM U987, INSERM, Paris, France

${ }^{3}$ Anesthesia department, Hôpital Raymond-Poincaré, Garches, France

Correspondence to Dr Hakim Harkouk, Anesthesia, Hopital Ambroise-Pare, Boulogne-Billancourt 92104, France; hakim.harkouk@aphp.fr

Received 19 August 2020 Revised 12 October 2020 Accepted 23 November 2020 Published Online First

7 January 2021
Check for updates

(C) American Society of Regional Anesthesia \& Pain Medicine 2021. Re-use permitted under CC BY-NC. No commercial re-use. Published by BMJ.

To cite: Harkouk $\mathrm{H}_{\text {, }}$

Fletcher D, Martinez V.

Reg Anesth Pain Med

2021:46:251-257.

\section{ABSTRACT}

Patients frequently report chronic postsurgical pain (CPSP) after breast cancer surgery (BCS). The paravertebral block (PVB) is an effective technique to reduce acute postoperative pain after BCS, but its efficacy in preventing CPSP is unclear. This meta-analysis evaluates the efficacy of PVB in preventing CPSP after BCS. We searched Medline, Embase, CENTRAL, Database of Abstracts of Reviews of Effects, ClinicalTrials.gov, and WHO International Clinical Trials Registry Platform for studies comparing PVB with control for CPSP prevention after BCS, from inception to April 2020. The primary outcome was CPSP at 6 months, and the secondary outcomes were CPSP at 3 and 12 months, chronic postsurgical neuropathic pain (CPSNP) at 6 months, and PVB-related complications. Data were pooled and analyzed with a random-effects model, and the Grading of Recommendations, Assessment, Development and Evaluations (GRADE) system was used to evaluate the certainty of evidence. A total of 12 studies were included in the study; data for the 6-month time point from 7 studies (2161 patients) were analyzed, and no difference was found between PVB and control in terms of efficacy in preventing CPSP after BCS (risk ratio (RR) 0.82 (95\% $\mathrm{Cl} 0.62$ to 1.08$)$ ), with a moderate quality of evidence according to the GRADE system. Similar results were obtained at 3 and 12 months (RR $0.78(95 \% \mathrm{Cl} 0.57$ to 1.06), RR 0.45 ( $95 \%$ Cl 0.14 to 1.41), respectively). Data for the 12-month time point from seven studies (2087 patients) were analyzed and showed that PVB protected against CPSNP, with low quality of evidence (RR 0.51 (95\% Cl 0.31 to 0.85$)$ ). In conclusion, CPSP was not found significantly prevented by PVB after BCS despite the limits in the included studies; nevertheless, PVB could prevent CPSNP by impacting the transition from acute to chronic pain.

\section{INTRODUCTION}

Breast cancer is the most frequently diagnosed tumor in women, with an incidence of more than one million new cases per year. ${ }^{1}$ Its prognosis has improved over the last decade with advances in surgery and adjuvant treatments. ${ }^{2}$ Chronic postsurgical pain (CPSP), defined as pain lasting for more than 3 months after surgery, ${ }^{3}$ is frequently reported by patients undergoing breast cancer surgery (BCS), with a prevalence of up to $35 \% .^{4}$ This pain may have a number of causes: the intercostobrachial nerve may be damaged, phantom and neuropathic pain may result from injury to the nerves, and neuromas may form in the scar tissue..$^{5-7}$ Some studies also suggested that women with breast cancer who undergo radiotherapy have a lifelong risk of developing chronic postsurgical neuropathic pain (CPSNP). ${ }^{8}{ }^{9}$ Furthermore, CPSP affects the quality of life of cancer survivors ${ }^{10} 11$ and increases healthcare costs. $^{12}$

The perioperative pain management appeared as a major point to reduce the risk of chronification of pain after surgical trauma. ${ }^{13}$ The possibility of preventing CPSP by specific interventions, such as regional analgesia (RA), has been reviewed. ${ }^{13}$ RA may prevent CPSP by limiting the nervous system remodeling that occurs when a persistent nociceptive stimulus is applied, resulting in hyperalgesia, allodynia, and sustained wound pain. ${ }^{14}$

The paravertebral block (PVB) is an RA technique that involves the injection of local anesthetic close to the spinal nerves emerging from the intervertebral foramina. ${ }^{15}$ PVB is an effective technique in reducing acute postoperative pain after breast surgery. ${ }^{16}$ Two systematic reviews have suggested that PVB may also prevent the development of CPSP after breast surgery, but with a low certainty of evidence due to poor quality or limited power of the studies included. ${ }^{14}{ }^{18} \mathrm{~A}$ recent prospective randomized study of the largest sample to date suggested that PVB did not prevent CPSP after BCS. ${ }^{19}$

We hypothesize that the published information available has advanced and that it may now be possible to draw more reliable conclusions about the potential benefits of PVB in preventing CPSP after breast surgery.

In this systematic review, we aimed to update the published findings concerning the ability of PVB in reducing the risk of CPSP at 3, 6, and 12 months after BCS.

\section{METHODS}

Data sources and search strategy

The study was registered with the International Prospective Register of Systematic Reviews (PROSPERO; CRD42020183041). This systematic review of randomized controlled trials (RCTs) and observational studies was performed in accordance with the criteria of the Preferred Reporting Items for Systematic Reviews and Meta-Analyses statement and the current recommendations of the Cochrane Collaboration. ${ }^{20}$ We searched CENTRAL, Medline and Embase databases for studies included from database inception to April 24, 2020, with no limitations on publication language or status, using the terms 'chronic postsurgical pain, persistent postoperative pain, paravertebral nerve block, paravertebral block, breast surgery and breast cancer surgery'. We identified RCTs with the highly 
sensitive search strategy of the Cochrane Collaboration. ${ }^{21}$ We also searched the Database of Abstracts of Reviews of Effects for previous relevant systematic reviews, ClinicalTrials.gov, and the WHO International Clinical Trials Registry Platform for completed trials.

\section{Study selection}

We retained all studies including adults undergoing elective BCS. The intervention of interest was paravertebral nerve block performed with a single-injection technique (single-shot) or a catheter-based infusion (continuous), including single level or multiple levels, with any local anesthetic, at any dose, with or without adjuvants, and for any duration, versus conventional pain control. A single-injection technique (single-shot) could offer a single-level block or a multiple-level block and we extracted the data as cited in the studies. Two authors (VM and $\mathrm{HH}$ ) independently screened the titles, abstracts, and full manuscripts according to the selection criteria. Any disagreement was discussed with a third author (DF) until consensus was reached.

\section{Data extraction and assessment of risk of bias}

Two reviewers ( $\mathrm{HH}$ and $\mathrm{VM}$ ) independently extracted data from each study. Disagreements were resolved by consensus with a third reviewer (DF). We extracted information about the trials (first author, year of publication, country, number of arms in the study, and sponsorship), participants (characteristics of the population and number of patients randomized and analyzed), experimental intervention (PVB technique, anesthetic dose, and level of the nerve block) surgical technique, and adjuvant treatment. Two independent reviewers ( $\mathrm{HH}$ and VM) assessed the quality of the trial methodology with the Cochrane Risk of Bias Tool, with any discrepancies resolved by consensus. ${ }^{22}$

\section{Outcome measures}

The primary outcome was the proportion of patients reporting CPSP at 6 months. We considered CPSP as defined by the authors. The type (ie, any pain, neuropathic) and the site (breast, armpit, arm, and other sites) of pain were identified. The secondary outcomes were the proportions of patients developing CPSP at 3 and 12 months and CPSNP at 6 months after BCS. The method used to assess CPSNP was extracted from the studies.

\section{Data synthesis and analysis}

For the proportion of patients with CPSP, the treatment effect was presented as risk ratio (RR), with 95\% CI, for dichotomous data. Heterogeneity was expected and we therefore used the DerSimonian and Laird random-effects meta-analysis models. We assessed statistical heterogeneity by inspecting the graphs and calculating the $\mathrm{I}^{2}$ statistic, which describes the proportion of the variability of effect estimates attributable to heterogeneity rather than sampling error. We interpreted the value of the $\mathrm{I}^{2}$ statistic using the following thresholds: 0\%-40\%: may not be important; 30\%-60\%: may represent moderate heterogeneity; 50\%-90\%: may represent substantial heterogeneity; and $75 \%-100 \%$ : considerable heterogeneity. ${ }^{23}$

\section{Rating of evidence quality}

We present the primary outcomes of the review in the 'Summary of findings' tables, as recommended in the Cochrane Handbook for Systematic Reviews of Interventions. The quality of evidence for each outcome was rated according to the Grading of Recommendations, Assessment, Development and Evaluations (GRADE) Working Group system, ${ }^{24}$ in five points: risk of

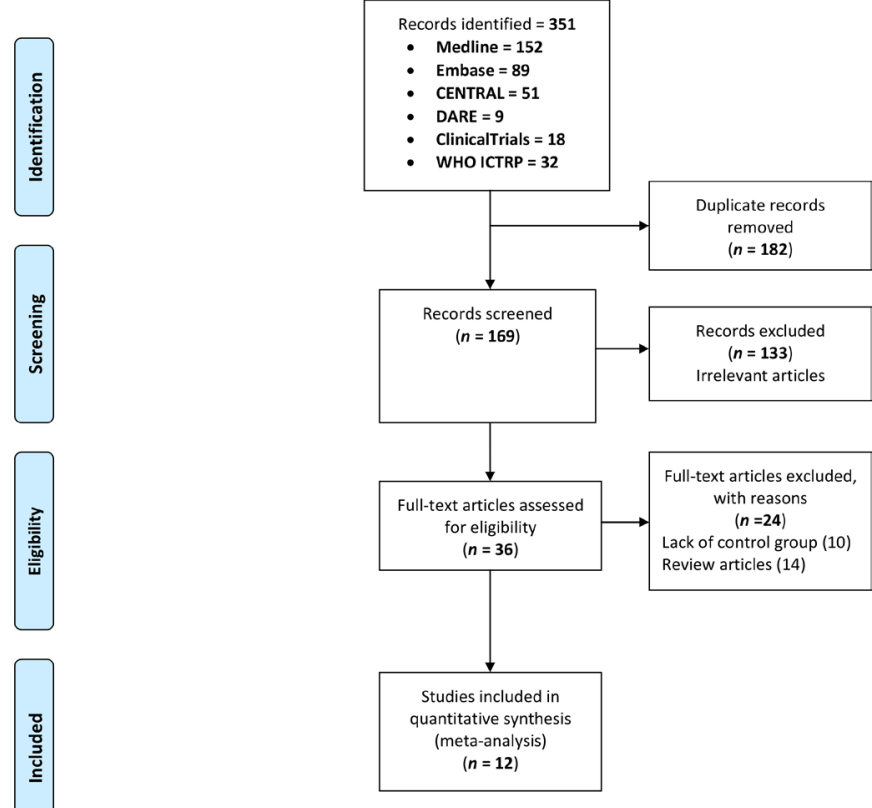

Figure 1 Study flow diagram. DARE, Database of Abstracts of Reviews of Effects; ICTRP, International Clinical Trials Registry Platform.

bias, inconsistency, indirectness, imprecision, and publication bias. Each point was rated independently by two authors $(\mathrm{HH}$ and VM), with discussion to reach consensus if necessary.

\section{RESULTS}

\section{Description of studies}

The literature search identified 36 potentially eligible studies. Following screening of the title and abstract alone, 24 studies were excluded because they lacked a control group $(n=10)$ or were review articles $(n=14)$. We therefore included 12 full-text studies in total in the systematic review and meta-analysis. ${ }^{519}$ 25-34 The literature search process is summarized in figure 1. In total, 2403 patients, randomized to PVB $(n=1221)$ or control $(n=1182)$, were included in the 12 studies retained. The characteristics of the included studies and the surgical and PVB techniques used are presented in table 1 . The relevant outcomes are presented in table 2. The risk of bias is presented in the bias graph (figure 2).

\section{Primary outcomes}

Among the 12 studies, 7 diagnosed CPSP at 6 months after BCS. CPSP was identified in 507 of 1102 patients (46\%) in the PVB group and 527 of 1059 patients (49\%) in the control group. This difference was not statistically significant (RR 0.82 (95\% CI 0.62 to 1.08$)$ ) (figure 3 ). The quality of evidence according to the GRADE system was moderate due to heterogeneity $\left(\mathrm{I}^{2}=51 \%\right)$ (table 3).

\section{Secondary outcome}

Among the 12 studies, 6 diagnosed CPSP at 3 months after BCS. CPSP was identified in 108 of 237 patients (45\%) in the PVB group and 108 of 183 patients (59\%) in the control group. The difference in CPSP rates at 3 months did not differ significantly between the PVB and the control group (RR 0.78 (95\% CI 0.57 to 1.06)). The GRADE quality of evidence was moderate due to imprecision, with the optimal information size not reached (table 3). 
Table 1 Summary of the characteristics of the included studies and the surgical and PVB techniques

\begin{tabular}{|c|c|c|c|c|c|}
\hline Study & PVB technique & Complications & Type of surgery & Adjuvant therapy & Other CPSP factors \\
\hline Iohom et $a l^{25}$ & $\begin{array}{l}\text { Anatomical, continuous, single } \\
\text { level }\end{array}$ & $\begin{array}{l}\text { One ipsilateral Horner's } \\
\text { syndrome }\end{array}$ & $\begin{array}{l}\text { Lumpectomy, simple } \\
\text { mastectomy, AND }\end{array}$ & Chemotherapy, radiotherapy & None \\
\hline Kairaluoma et a $\left.\right|^{5}$ & $\begin{array}{l}\text { Anatomical, single shot, single } \\
\text { level }\end{array}$ & Not reported & $\begin{array}{l}\text { Simple mastectomy, LNB, } \\
\text { LND }\end{array}$ & Chemotherapy, radiotherapy & Repeated surgery \\
\hline
\end{tabular}

$\begin{array}{lllll}\text { Ibarra et }_{\left.\mathrm{a}\right|^{28}} & \begin{array}{l}\text { Neurostimulation, single shot, } \\ \text { unknown }\end{array} & \text { One Horner's syndrome } & \text { MRM } & \text { Chemotherapy, radiotherapy } \\ \mathrm{Xu}^{34} & \text { Ultrasound, single shot, single } & \text { Not reported } & \text { RM } & \text { None reported }\end{array}$

\begin{tabular}{|c|c|c|c|c|c|}
\hline Elkaradawy et $a /^{33}$ & $\begin{array}{l}\text { Ultrasound, continuous, single } \\
\text { level }\end{array}$ & Not reported & Lumpectomy, AND & Chemotherapy, radiotherapy & None \\
\hline $\mathrm{Lee}^{32}$ & $\begin{array}{l}\text { Anatomical, continuous, single } \\
\text { level }\end{array}$ & $\begin{array}{l}\text { Four failures } \\
\text { Four dislodged catheters }\end{array}$ & Lumpectomy, SM, AND & Chemotherapy & $\begin{array}{l}\text { Repeated surgery } \\
\text { Postoperative allodynia } \\
\text { days } 1,2 \text {, and } 3 \text { and } \\
\text { month } 3\end{array}$ \\
\hline
\end{tabular}

\begin{tabular}{|c|c|c|c|c|c|}
\hline Karmakar et a/ ${ }^{30}$ & $\begin{array}{l}\text { Anatomical, single shot vs } \\
\text { continuous single level }\end{array}$ & No major complication & MRM & Chemotherapy, radiotherapy & None \\
\hline $\mathrm{Lam}^{31}$ & $\begin{array}{l}\text { Ultrasound, single shot, single } \\
\text { level }\end{array}$ & Not reported & Total mastectomy & Not reported & None \\
\hline Ilfeld et $\left.a\right|^{29}$ & $\begin{array}{l}\text { Ultrasound, continuous, single } \\
\text { level }\end{array}$ & Not reported & Simple mastectomy, LND & Not reported & None \\
\hline Abdallah et $a l^{26}$ & $\begin{array}{l}\text { Ultrasound, single shot, } \\
\text { multiple level }\end{array}$ & None & $\begin{array}{l}\text { Segmental mastectomy } \\
\text { with SLNB or ALND, total } \\
\text { mastectomy with or } \\
\text { without SLNB, MRM, and } \\
\text { SM with implant insertion }\end{array}$ & Chemotherapy, radiotherapy & $\begin{array}{l}\text { Breast reconstructive } \\
\text { surgery }\end{array}$ \\
\hline Gacio et $a l^{27}$ & $\begin{array}{l}\text { Anatomical, single shot, single } \\
\text { level }\end{array}$ & $\begin{array}{l}\text { Hypotension ( } 9 \text { vs } 3 \text { ) } \\
\text { Bradycardia ( } 12.5 \% \text { vs } 7.5 \% \text { ) } \\
\text { Pleural puncture without } \\
\text { PNO }\end{array}$ & SM, MRM, LND & Chemotherapy, radiotherapy & None \\
\hline Sessler et al ${ }^{19}$ & $\begin{array}{l}\text { Ultrasound, single shot, } \\
\text { multiple level }\end{array}$ & $\begin{array}{l}\text { No major complication } \\
\text { observed }\end{array}$ & $\begin{array}{l}\text { Simple mastectomy, MRM, } \\
\text { LND }\end{array}$ & Chemotherapy, radiotherapy & None \\
\hline
\end{tabular}

ALND, axillary lymph node dissection; AND, axillary node dissection; CPSP, chronic postsurgical pain; LNB, lymph node biopsy; LND, lymph node dissection; MRM, modified radical mastectomy; PNO, pneumothorax; PVB, paravertebral block; RM, radical mastectomy; SLNB, sentinel lymph node biopsy; SM, simple mastectomy.

Among the 12 studies, 4 diagnosed CPSP at 12 months after BCS. CPSP was diagnosed in 245 of 914 patients (26\%) in the PVB group and 261 of 930 patients (28\%) in the control group. This difference was not statistically significant (RR 0.45 (95\% CI 0.14 to 1.41$)$ ). The GRADE quality of evidence was moderate due to heterogeneity $\left(\mathrm{I}^{2}=82 \%\right)$ (table 3$)$. CPSNP, diagnosed 6 months after surgery, was analyzed in seven trials, $51926-2933$ and a significant difference was found between the PVB and the control group (RR CI 0.51 (95\% CI 0.31 to 0.85)) (figure 4). The GRADE quality of evidence was low due to heterogeneity $\left(\mathrm{I}^{2}=59 \%\right)$ and performance bias (table 3$)$.

Two trials identified Horner's syndrome as a complication of $\mathrm{PVB}^{25}{ }^{28}$; one trial identified hypotension (nine patients), bradycardia (four patients), and a case of pleural puncture without pneumothorax ${ }^{27}$; one identified four dislodged catheters ${ }^{32}$; and no major complication was diagnosed in three trials. ${ }^{19} 2630$ No statistical difference was found between groups and the complications of PVB were not reported in five trials. 529313334

\section{DISCUSSION}

Our meta-analysis provides reliable results suggesting that the use of PVB does not significantly influence the development of CPSP not only at 6 months, but also at 3 and 12 months after BCS. The sample size collected from existing publications provides a solid basis for this finding, which is consistent with the results of the most recent large prospective study. ${ }^{19}$ However, our results suggest that PVB may influence the development of neuropathic pain 12 months after BCS.

\section{PVB for preventing chronic pain after BCS}

We found no protective effect of PVB on CPSP 6 months after surgery (RR 0.82 (95\% CI 0.62 to 1.08$)$ ). This finding is supported by a moderate quality of evidence due to residual heterogeneity $\left(\mathrm{I}^{2}=51 \%\right)$. This absence of a preventive effect was confirmed at 3 and 12 months postsurgery. Contrary to our results, the most recent literature reviews have concluded that PVB can limit the incidence of CPSP 6 months after BCS. ${ }^{14} 18$ Our results also contrast with those of Cochrane meta-analyses reporting that various regional anesthesia techniques, including PVB, nerve blocks, and local infiltration, can prevent chronic postoperative pain after BCS. In both these meta-analyses, the studies included were characterized by small sample sizes, with few positive studies (one in six and two in seven, respectively) suggesting a protective effect of PVB on CPSP. The most recent and largest RCT, which was not primarily designed for the CPSP outcome, reported no protective effect of PVB in the prevention of CPSP at 12 months. Combining all the available studies in our meta-analysis, including the trial performed by Sessler et al, ${ }^{19}$ we found no clinical effect of PVB on CPSP after breast surgery at 3,6 , or 12 months. Our sample was significantly larger than that for the most recent meta-analysis in the field, ${ }^{14}$ with $493 \%$ more patients (2161 patients vs 439 patients). The discrepancy concerning the effect of PVB at 6 months reported by Hussain et $a l^{14}$ seems to be related principally to the addition of the results from the study by Sessler et al. The sample size analysis based on Trial Sequential Analysis (TSA method) performed by Hussain et al suggested that the pooled results were underpowered to 
Review

Table 2 Summary of the characteristics of the study populations of the included trials

\begin{tabular}{|c|c|c|c|c|c|c|c|c|}
\hline Study & Pain outcome & $\begin{array}{l}\text { Follow-up } \\
\text { (months) }\end{array}$ & $\begin{array}{l}\text { Site of chronic } \\
\text { pain }\end{array}$ & $\begin{array}{l}\text { Pain assessment } \\
\text { method }\end{array}$ & $\begin{array}{l}\text { Neuropathic pain } \\
\text { questionnaire }\end{array}$ & $\begin{array}{l}\text { Presurgical } \\
\text { assessment }\end{array}$ & $\begin{array}{l}\text { Physical } \\
\text { function }\end{array}$ & $\begin{array}{l}\text { Psychological } \\
\text { follow-up }\end{array}$ \\
\hline lohom et $a l^{25}$ & $\begin{array}{l}\text { Pain/no pain } \\
\text { (PPI and PRI) }\end{array}$ & $2-3$ & Unspecified & $\begin{array}{l}\text { McGill Pain } \\
\text { Questionnaire } \\
\text { (LF) }\end{array}$ & None & HADS & None & HADS 10 weeks \\
\hline Kairaluoma et $\left.a\right|^{5}$ & NRS $>3$ & 6 and 12 & $\begin{array}{l}\text { Breast, axilla, arm, } \\
\text { and other sites }\end{array}$ & NRS & $\begin{array}{l}\text { Clinical } \\
\text { examination, QST, } \\
\text { and questions }\end{array}$ & $\begin{array}{l}\text { Profile of Mood } \\
\text { Scales }\end{array}$ & $\begin{array}{l}\text { Ipsilateral } \\
\text { shoulder } \\
\text { function }\end{array}$ & $\begin{array}{l}\text { Profile of Mood } \\
\text { Scales (M1, 3, and 6) }\end{array}$ \\
\hline Ibarra et $\left.a\right|^{28}$ & $\begin{array}{l}\text { Phantom or } \\
\text { neuropathic pain }\end{array}$ & 5 & $\begin{array}{l}\text { Breast, axilla, arm, } \\
\text { and other sites }\end{array}$ & None & Questions & Not reported & None & None \\
\hline $\mathrm{Xu}^{34}$ & Pain/no pain & 3 and 6 & Unspecified & None & None & Not reported & None & None \\
\hline Elkaradawy et a $\beta^{33}$ & $\begin{array}{l}\text { Neuropathic } \\
\text { pain }\end{array}$ & 3,6 , and 9 & $\begin{array}{l}\text { Breast, axilla, and } \\
\text { arm }\end{array}$ & None & $\begin{array}{l}\text { Neuropathic Pain } \\
\text { Scale }\end{array}$ & $\begin{array}{l}\text { Depression, } \\
\text { preoperative pain, } \\
\text { chemotherapy, and } \\
\text { radiotherapy }\end{array}$ & $\begin{array}{l}\text { Work and } \\
\text { sleep }\end{array}$ & Mood \\
\hline Lee $^{32}$ & Pain/no pain & 3 & Any site & $\begin{array}{l}\text { McGill Pain } \\
\text { Questionnaire (SF) }\end{array}$ & None & $\begin{array}{l}\text { BPI, PCS, HADS, } \\
\text { STAI }\end{array}$ & None & BPI, PCS, HADS \\
\hline Karmakar et a $\left.\right|^{30}$ & Pain/no pain & 3 and 6 & Any site & VRS & & SF-36 & $\begin{array}{l}\text { Physical health } \\
\text { SF-36 }\end{array}$ & Mental health SF-36 \\
\hline $\mathrm{Lam}^{31}$ & Pain/no pain & 6 & Unspecified & None & LANSS score & Not reported & None & None \\
\hline Ilfeld et $\left.a\right|^{29}$ & $\begin{array}{l}\text { No pain-worst } \\
\text { pain }\end{array}$ & 3 and 12 & Unspecified & NRS/BPI & Phantom pain & Not reported & BPI and sleep & BPI \\
\hline Abdallah et $a^{26}$ & $\begin{array}{l}\text { Neuropathic } \\
\text { pain }\end{array}$ & 6 & $\begin{array}{l}\text { Breast, chest, axilla, } \\
\text { and arm }\end{array}$ & NRS & $\begin{array}{l}\text { DN4/CNP grading } \\
\text { system }\end{array}$ & Not reported & None & None \\
\hline Gacio et $a l^{27}$ & Pain/no pain & 6 & Breast and arm & None & DN4 & $\begin{array}{l}\text { HADS, preoperative } \\
\text { pain, and family } \\
\text { support }\end{array}$ & $\begin{array}{l}\text { EORTC } \\
\text { QLQ-C30, } \\
\text { EORTC QLQ- } \\
\text { BR23 }\end{array}$ & $\begin{array}{l}\text { EORTC QLQ-C30, } \\
\text { EORTC QLQ-BR23 }\end{array}$ \\
\hline Sessler et al ${ }^{19}$ & Pain/no pain & 6 and 12 & $\begin{array}{l}\text { Not reported (not } \\
\text { designed for CPSP) }\end{array}$ & $\mathrm{BPI}$ & $\begin{array}{l}\text { Neuropathic Pain } \\
\text { Questionnaire (SF) }\end{array}$ & $\begin{array}{l}\text { Chemotherapy and } \\
\text { radiotherapy }\end{array}$ & SF-12 & SF-12 \\
\hline
\end{tabular}

BPI, Brief Pain Inventory; CNP, chronic neuropathic pain; CPSP, chronic postsurgical pain; DN4, Douleurs Neuropathiques Par 4; EORTC QLQ BR23/C30, European Organisation for Research and Treatment of Cancer Quality of Life Questionnaire; HADS, Hospital Anxiety and Depression Scale; LANSS, Leeds Assessment of Neuropathic Symptoms and Signs; LF, long form; NRS, Numeric Rating Scale; PCS, Pain Catastrophizing Scale; PPI, present pain intensity; PRI, Pain Rating Index; QST, quantitative sensory testing; SF, short form; STAl, State-Trait Anxiety Inventory; VRS, Verbal Rating Scale.

demonstrate an effect of treatment at 6 months. According to their calculation, the amount of data available for the 6-month time point in the study may be sufficient for reliable confirmation of the absence of decrease in $\mathrm{RR} \geq 30 \%$, but it does not exclude the possibility of a smaller decrease in the risk of CPSP. Our results are, therefore, consistent with those of the largest available RCT, ${ }^{19}$ suggesting that no effect is detectable 6 months after BCS.

The results of this meta-analysis suggest that the incidence of CPSNP 6 months after BCS may be 52\% lower in the PVB group, with a low quality of evidence. The number needed to treat estimates suggested that $12(7-56)$ patients would need to be treated by PVB to prevent CPSNP in one patient (table 3). These results are consistent with published findings suggesting that prolonged afferent interruption by intercostal blocks or thoracic epidurals may reduce the risk of CPSNP. ${ }^{35}$ CPSNP

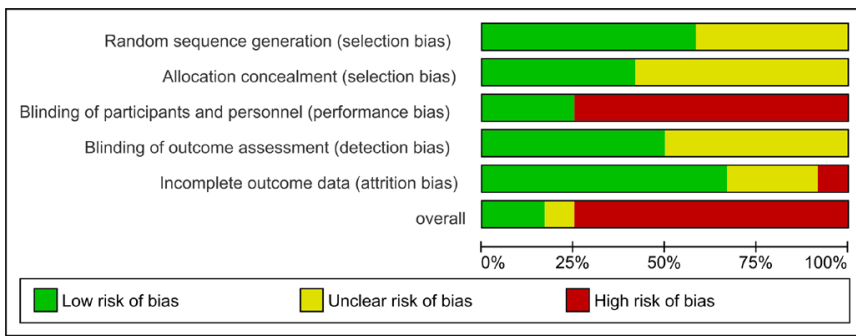

Figure 2 Risk of bias graph. involves specific mechanisms, such as nerve trauma (intercostobrachial neuralgia, injury to the nerves innervating the breast and armpit), leading to the spontaneous generation of ectopic impulses and exaggerated excitability, affecting the injured and even uninjured neighboring sensory afferents. The profound analgesic effect of regional anesthesia, such as PVB, may reduce the sensitization underlying CPSNP, therefore accounting for the specific preventive effect on CPSNP. ${ }^{36}$ This preventive effect may be of potential interest because the prevalence of CPSNP is high after breast surgery, exposing patients to a specific disease burden. ${ }^{37}$ Unfortunately, most studies evaluating the incidence of CPSP after breast surgery do not monitor neuropathic characteristics or use very heterogeneous evaluation tools. In our review, only 5 of the 12 studies provided this information, and the tools used for evaluation were heterogeneous. Our results suggest that further prospective studies are required and should evaluate neuropathic pain specifically, through validated approaches using a standardized grading system including clinical examination. ${ }^{38}$ Such studies would provide more information about the potential benefits of PVB in preventing CPSNP development.

\section{Heterogeneity of the population: PVB and surgery}

The patients underwent various types of surgery and it was not possible to propose a subgroup analysis of this factor. Both type of surgery and additional surgical traumas, such as axillary lymph node dissection, can modify the frequency of CPSP. ${ }^{39}$ This surgical heterogeneity clearly reduces the validity of our results. Adjuvant treatments (ie, chemotherapy and radiotherapy) were 


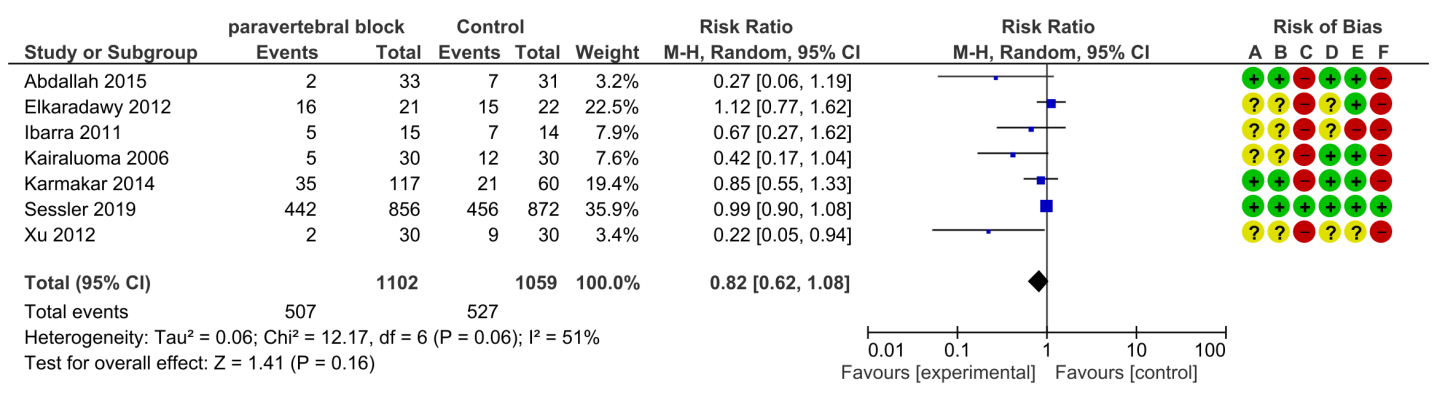

Risk of bias legend

(A) Random sequence generation (selection bias)

(B) Allocation concealment (selection bias)

(C) Blinding of participants and personnel (performance bias)

(D) Blinding of outcome assessment (detection bias)

(E) Incomplete outcome data (attrition bias)

(F) overall

Figure 3 Forest plot of paravertebral block chronic postsurgical pain prevention at 6 months.M-H, Mantel-Haenszel.

offered to $75 \%$ of the patients included in this review, and this factor did not seem to contribute significantly to the heterogeneity of the population.

RA, whatever the site to which the local anesthetic is delivered, is considered one of the most efficient analgesic techniques after surgery. PVB has been shown to be effective against acute pain after breast surgery and is equivalent to epidural analgesia. ${ }^{5}$ A link between the severity of acute pain and the development of CPSP has been suggested, providing support for aggressive treatments of acute pain to prevent CPSP. ${ }^{40}$ One crucial issue is the confirmation of nerve block efficacy in preventing CPSP. Confirmation of the nerve block before or after surgery was performed and obtained in only 2 of the 12 studies included in this review. The heterogeneity of the PVB techniques has been previously shown to result in diverse levels of efficacy in CPSP prevention. ${ }^{14}$ Indeed, the optimal approach (ie, continuous PVB or multilevel injection) was used in only 7 of the 12 studies. This heterogeneity in techniques and the lack of nerve block confirmation may result in the absence of real protection against CPSP. Furthermore, this invasive technique causes a number of adverse events (AEs). The reporting of such events was totally absent from $40 \%$ of the studies included. In the seven studies reporting AEs, the events cited were minor (pleural puncture, technical failure, Claude Bernard-Horner's syndrome, hypotension, and bradycardia). Improvements in technique based on ultrasound localization of the needle may decrease the frequency of AEs further. In conclusion, questions remain about whether the optimal PVB was used both to control acute pain and to prevent chronic pain, but the usual practice described in these studies is sufficient to test the hypothesis of clinical benefit from PVB. This technique does not seem to improve CPSP outcomes after breast surgery.

\section{Strengths and limitations of the meta-analysis}

Our meta-analysis has several strengths. Our exhaustive search included all electronic databases and had no language restrictions. Our review contained more RCTs and a 493\% larger sample for the 6-month time point than the most recent meta-analysis by Hussain et al. It provides reliable validity for the negative results, for a 30\% decrease in RR for CPSP at 6 months. We were also able to analyze the effects of PVB at 3 and 12 months after surgery, making it possible to paint a general picture of the effect after surgery. Finally, through subpopulation analysis, we were able to suggest a specific impact of PVB on the development of CPSNP.

Our meta-analysis also has several weaknesses. First, variability in terms of the type of surgery and PVB intervention may have caused significant heterogeneity. Heterogeneity of data is represented by the $\mathrm{I}^{2}$ score, which was taken into account in the GRADE method for level of evidence. The GRADE integrates $\mathrm{I}^{2}$ score, optimal information on sample size, and bias. The certainty of evidence was thus considered to range from low to moderate. Second, analyzing single-shot versus multiple levels and single-shot versus continuous infusion is of importance. Due to the heterogeneity of the techniques used in the studies, it was not possible to run a subgroup analysis. For instance and concerning the primary endpoint at 6 months, among the seven

Table 3 Summary of results

\begin{tabular}{|c|c|c|c|c|c|c|c|}
\hline Outcomes & Trials $(\mathrm{n})$ & Included studies & Participants (n) & $\begin{array}{l}\text { RR, random effect } \\
(95 \% \mathrm{Cl})\end{array}$ & $\begin{array}{l}\text { Heterogeneity } \\
\left(I^{2}\right)(\%)\end{array}$ & $\begin{array}{l}\text { Quality of evidence } \\
\text { (GRADE) }\end{array}$ & NNT \\
\hline $\begin{array}{l}\text { Incidence of CPSP at } 3 \\
\text { months }\end{array}$ & 6 & $25293032-34$ & 420 & $0.78(0.57$ to 1.06$)$ & 49 & $\oplus \oplus \oplus \ominus 2$ & NA \\
\hline $\begin{array}{l}\text { Incidence of CPSP at } 6 \\
\text { months }\end{array}$ & 7 & 5192628303334 & 2161 & 0.82 (0.62 to 1.08$)$ & 51 & $\oplus \oplus \oplus \ominus 1$ & NA \\
\hline $\begin{array}{l}\text { Incidence of CPSP at } 12 \\
\text { months }\end{array}$ & 3 & 51929 & 1826 & $0.45(0.14$ to 1.41$)$ & 82 & $\oplus \oplus \oplus \ominus 1$ & NA \\
\hline $\begin{array}{l}\text { Incidence of CPSNP at } 6 \\
\text { months }\end{array}$ & 8 & $51926-293133$ & 2087 & $0.48(0.27$ to 0.85$)$ & 59 & $\oplus \oplus \ominus \ominus 1,3$ & $12.0(7-56)$ \\
\hline
\end{tabular}

Primary outcome: The level of evidence was assessed by the GRADE method, from very low $\oplus \ominus \ominus \Theta$ to high $\oplus \oplus \oplus \oplus$. 1: downgrade for inconsistency $\left(1^{2}>50 \%\right)$ : serious; 2 : downgrade for imprecision: optimal information size not reached: very serious; 3 : downgrade for bias.

CPSNP, chronic postsurgical neuropathic pain; CPSP, chronic postsurgical pain; GRADE, Grading of Recommendations, Assessment, Development and Evaluations; NA, not applicable; NNT, number needed to treat; RR, risk ratio. 


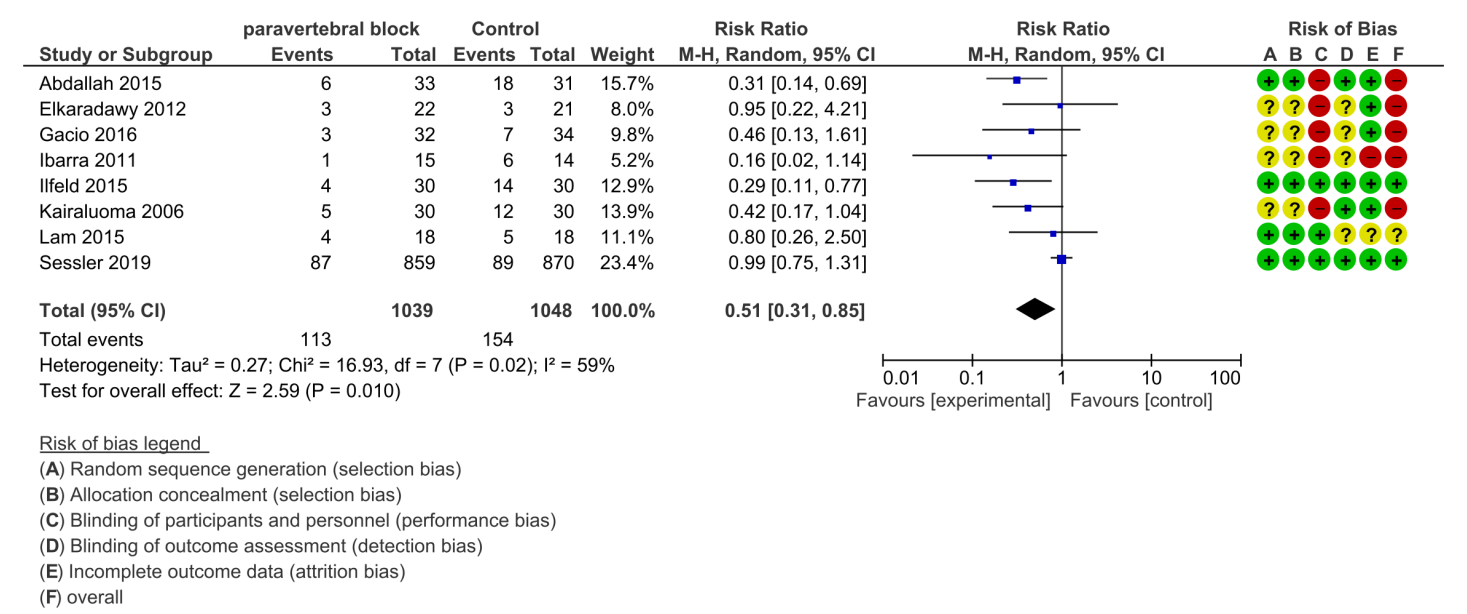

Figure 4 Forest plot of paravertebral block chronic postsurgical neuropathic pain prevention at 6 months. M-H, Mantel-Haenszel.

available studies, six used a single-shot technique and only one a continuous infusion technique, precluding the analysis between these two unbalanced subgroups. Finally, many other factors, such as preoperative chronic pain and psychological or genetic conditions conferring a predisposition to CPSP following breast surgery, were not analyzed in this review. ${ }^{41}$

\section{Agenda for future research}

Homogeneity in the design of future RCTs is necessary to avoid comparing different approaches. We propose a non-exhaustive list of items: harmonization of anesthesia technique: use of the same technical approach (eg, ultrasound-guided technique), information on single or continuous infusion administration, and single-level or multiple-level block; harmonization of the type of surgery and/or stratification between invasive and less invasive technique; standardization of CPSP definition as reported in the International Classification of Diseases 11th Revision proposed by the International Association for the Study of Pain; and homogenization of pain assessment method.

\section{CONCLUSION}

In conclusion, CPSP was not found significantly prevented by PVB after BCS despite limitations in the included studies; nevertheless, PVB could prevent CPSNP by impacting the transition from acute to chronic pain.

Contributors $\mathrm{HH}$ contributed to the implementation of the research, analysis of the results, and writing of the manuscript. DF helped in the analysis of the results and in writing the manuscript. VM contributed to the design and implementation of the research, analysis of the results, and writing of the manuscript.

Funding This work received support from the EU/EFPIA/Innovative Medicines Initiative (2) Joint Undertaking (IMI-PAINCARE) (grant no. 777500).

Disclaimer The statements and opinions presented here reflect the authors' view, and neither IMI nor the European Union, EFPIA, or any associated partners are responsible for any use that may be made of the information contained herein ( www.imi.europa.eu; www.imi-paincare.eu).

Competing interests None declared.

Patient consent for publication Not required.

Provenance and peer review Not commissioned; externally peer reviewed.

Data availability statement All data relevant to the study are included in the article or uploaded as supplementary information. Protocol and supplemental data are available upon request.

Open access This is an open access article distributed in accordance with the Creative Commons Attribution Non Commercial (CC BY-NC 4.0) license, which permits others to distribute, remix, adapt, build upon this work non-commercially, and license their derivative works on different terms, provided the original work is properly cited, an indication of whether changes were made, and the use is noncommercial. See: http://creativecommons.org/licenses/by-nc/4.0/.

ORCID iD

Hakim Harkouk http://orcid.org/0000-0003-4030-1708

\section{REFERENCES}

1 Bray F, Ferlay J, Soerjomataram I, et al. Global cancer statistics 2018: GLOBOCAN estimates of incidence and mortality worldwide for 36 cancers in 185 countries. CA Cancer J Clin 2018;68:394-424.

2 Miller KD, Nogueira L, Mariotto $A B$, et al. Cancer treatment and survivorship statistics, 2019. CA Cancer J Clin 2019;69:363-85.

3 Treede R-D, Rief W, Barke A, et al. Chronic pain as a symptom or a disease: the IASP classification of chronic pain for the International classification of diseases (ICD-11). Pain 2019;160:19-27.

4 Wang L, Cohen JC, Devasenapathy N, et al. Prevalence and intensity of persistent post-surgical pain following breast cancer surgery: a systematic review and metaanalysis of observational studies. Br J Anaesth 2020;125:346-57.

5 Kairaluoma PM, Bachmann MS, Rosenberg PH, et al. Preincisional paravertebral block reduces the prevalence of chronic pain after breast surgery. Anesth Analg 2006;103:703-8

6 Jung BF, Ahrendt GM, Oaklander AL, et al. Neuropathic pain following breast cancer surgery: proposed classification and research update. Pain 2003;104:1-13.

7 Wallace MS, Wallace AM, Lee J, et al. Pain after breast surgery: a survey of 282 women. Pain 1996;66:195-205.

8 Johansson S, Svensson H, Denekamp J. Timescale of evolution of late radiation injury after postoperative radiotherapy of breast cancer patients. Int J Radiat Oncol Biol Phys 2000;48:745-50

9 Bajrovic A, Rades D, Fehlauer F, et al. Is there a life-long risk of brachial plexopathy after radiotherapy of supraclavicular lymph nodes in breast cancer patients? Radiother Oncol 2004;71:297-301.

10 Macdonald L, Bruce J, Scott NW, et al. Long-term follow-up of breast cancer survivors with post-mastectomy pain syndrome. Br J Cancer 2005;92:225-30.

11 Peuckmann V, Ekholm 0, Rasmussen NK, et al. Chronic pain and other sequelae in long-term breast cancer survivors: nationwide survey in Denmark. Eur J Pain 2009; 13:478-85

12 Blyth FM, March LM, Brnabic AJM, et al. Chronic pain and frequent use of health care. Pain 2004;111:51-8.

13 Kehlet $\mathrm{H}$, Jensen TS, Woolf CJ. Persistent postsurgical pain: risk factors and prevention Lancet 2006;367:1618-25.

14 Hussain N, Shastri U, McCartney CJL, et al. Should thoracic paravertebral blocks be used to prevent chronic postsurgical pain after breast cancer surgery? A systematic analysis of evidence in light of IMMPACT recommendations. Pain 2018;159:1955-71.

15 Batra RK, Krishnan K, Agarwal A. Paravertebral block. J Anaesthesiol Clin Pharmacol 2011;27:5-11.

16 Santonastaso DP, de Chiara A, Russo E, et al. Single shot ultrasound-guided thoracic paravertebral block for opioid-free radical mastectomy: a prospective observational study. J Pain Res 2019;12:2701-8.

17 Saporito A, Aguirre J, Borgeat A, et al. Persistent postdischarge pain and chronic postoperative pain after breast cancer surgery under general anesthesia and singleshot paravertebral block: incidence, characteristics and impact on quality of life and healthcare costs. J Pain Res 2019;12:1193-9. 
18 Weinstein EJ, Levene JL, Cohen MS, et al. Local anaesthetics and regional anaesthesia versus conventional analgesia for preventing persistent postoperative pain in adults and children. Cochrane Database Syst Rev 2018;4:CD007105.

19 Sessler DI, Pei L, Huang Y, et al. Recurrence of breast cancer after regional or general anaesthesia: a randomised controlled trial. Lancet 2019;394:1807-15.

20 Liberati A, Altman DG, Tetzlaff J, et al. The PRISMA statement for reporting systematic reviews and meta-analyses of studies that evaluate healthcare interventions: explanation and elaboration. BMJ 2009;339:b2700.

21 Lefebvre C. Searching for studies. In: Cochrane Handbook for systematic reviews of interventions version 5.1.0. Chapter 6.4. The Cochrane Collaboration, 2011. www. cochranehandbook.org

22 Higgins JPT, Altman DG, Gøtzsche PC, et al. The Cochrane collaboration's tool for assessing risk of bias in randomised trials. BMJ 2011;343:d5928.

23 Higgins JPT, Thompson SG. Quantifying heterogeneity in a meta-analysis. Stat Med 2002:21:1539-58.

24 Balshem $\mathrm{H}$, Helfand $\mathrm{M}$, Schünemann $\mathrm{HJ}$, et al. GRADE guidelines: 3 . Rating the quality of evidence. J Clin Epidemiol 2011:64:401-6.

25 lohom G, Abdalla H, O'Brien J, et al. The associations between severity of early postoperative pain, chronic postsurgical pain and plasma concentration of stable nitric oxide products after breast surgery. Anesth Analg 2006;103:995-1000.

26 Abdallah FW, Morgan PJ, Cil T, et al. Comparing the DN4 tool with the IASP grading system for chronic neuropathic pain screening after breast tumor resection with and without paravertebral blocks: a prospective 6-month validation study. Pain 2015; 156:740-9.

27 Gacio MF, Lousame AMA, Pereira S, et al. Paravertebral block for management of acute postoperative pain and intercostobrachial neuralgia in major breast surgery. Braz J Anesthesiol 2016;66:475-84.

28 Ibarra MML, S-Carralero G-CM, Vicente GU, et al. [Chronic postoperative pain after general anesthesia with or without a single-dose preincisional paravertebral nerve block in radical breast cancer surgery]. Rev Esp Anestesio/ Reanim 2011;58:290-4.

29 Ilfeld BM, Madison SJ, Suresh PJ, et al. Persistent postmastectomy pain and pain-related physical and emotional functioning with and without a continuous paravertebral nerve block: a prospective 1-year follow-up assessment of a randomized, triple-masked, placebo-controlled study. Ann Surg Oncol 2015;22:2017-25.

30 Karmakar MK, Samy W, Li JW, et al. Thoracic paravertebral block and its effects on chronic pain and health-related quality of life after modified radical mastectomy. Reg Anesth Pain Med 2014;39:289-98.

31 Lam D. Paravertebral block vs. sham in the setting of a multimodal analgesia regimen and total intravenous anesthesia for mastectomy: a prospective, randomized, controlled trial. Cochrane library.

32 Lee P. A comparison of the effects of two analgesic regimens on the development of persistent post-surgical pain (PPSP) after breast surgery. J Rom Anest Terap Int 2013;20:83-93.

33 Elkaradawy S, Nasr M, Elkerm Y, et al. The effect of multimodal balanced anaesthesia and long term gabapentin on neuropathic pain, nitric oxide and interleukin-1 $\beta$ following breast surgery. Egypt J Anaesth 2012;28:67-78.

$34 \mathrm{Xu}$ J. Clinical evaluation of ultrasound-guided thoracic paravertebral block (TPVB) effect on postoperative analgesia in patients with breast cancer after radical mastectomy. Primary Health Care 2016;6.

35 Andreae MH, Andreae DA. Local anaesthetics and regional anaesthesia for preventing chronic pain after surgery. Cochrane Database Syst Rev 2012;10:CD007105.

36 Katz J, Seltzer Ze'ev. Transition from acute to chronic postsurgical pain: risk factors and protective factors. Expert Rev Neurother 2009;9:723-44.

37 Attal N, Lanteri-Minet M, Laurent B, et al. The specific disease burden of neuropathic pain: results of a French nationwide survey. Pain 2011;152:2836-43.

38 Finnerup NB, Haroutounian S, Kamerman P, et al. Neuropathic pain: an updated grading system for research and clinical practice. Pain 2016;157:1599-606.

39 Perkins FM, Kehlet $\mathrm{H}$. Chronic pain as an outcome of surgery. A review of predictive factors. Anesthesiology 2000;93:1123-33.

40 Fletcher D, Pogatzki-Zahn E, Zaslansky R, et al. euCPSP: European observational study on chronic post-surgical pain. Eur J Anaesthesiol 2011;28:461-2.

41 Andersen KG, Kehlet $H$. Persistent pain after breast cancer treatment: a critical review of risk factors and strategies for prevention. J Pain 2011;12:725-46. 